\title{
A mathematical model for the calculation of the thermal regime of the underground tunnel
}

\author{
Dmitriy Titkov* and Ilya Yarkov \\ Moscow State University of Civil Engineering, Yaroslavskoe shosse, 26, Moscow, 129337, Russia
}

\begin{abstract}
This paper deals with the problem of creation and sustenance of the thermal conditions of underground tunnel. Thermal conditions deal a great impact on the engineering communications work, electical cables conductivity and heat loss of the heat supply system. Suggested mathematical model allows to calculate the required thermal conditions of the underground tunnel and to predict it's change over time, depending on the season of the year and temperature of the supply air.
\end{abstract}

\section{Introduction}

Expansion of modern infrastructure and development of engineering systems leads to an increasing energy consumption and power of engineering equipment [1]. Underground tunnels for engineering systems are widely used, as they provide means for convenient installation of engineering systems and heat and electricity conduction [2]. Construction of such tunnels for engineering communications becomes more and more popular as it is crucial for the development of modern urban infrastructure. Required thermal and air conditions provide preservation and durability of engineering communications, which is important for human's safety and reliability of heat and energy supply of city districts [3]. This paper proposes a calculation model of thermal conditions of the underground tunnels. This is required to define changing over time air temperature and ground temperature with working mechanical ventilation [4]. Also this model considers changing over time temperature of outside air and internal excess heat, which affects heat loss of underground tunnels.

Part of an underground tunnel 250 meters long from supply to exhaust ventilation was taken as an object of research. Subject of research is thermal conditions of underground tunnel for engineering communication 250 meters long from supply to exhaust ventilation. Study of heat loss into ground, thermal conditions and microclimate parameters conducted: V.D. Machinskiy, G.I. Kuljinskiy, V.Y. Tsodikov, E.V. Kaznin, M.V. Bodrov, N.A. Parfenteva etc. But their methods don't allow to accurately measure changing of thermal conditions of underground tunnel with mechanical ventilation over time.

\footnotetext{
"Corresponding author: titkov1000@gmail.com
} 


\section{Methods of research}

Achievements of Russian and European scientists in the area of thermal conditions became basis of this work [5]. Main methods, used in this paper are: method of finite differences based on implicit solution scheme of a differential equations system, considering threedimensional problem while modeling nonstationary thermal field of ground and enclosing structures of underground tunnel; method of non-linear regression analysis of results of numerical solutions [6].

\section{Mathematical model for solving the problem}

There was developed a mathematical model of thermal conditions in the underground tunnel. It allows defining distribution and change of air temperature over the length of the tunnel and temperature of the ground, considering their mutual impact and change of the outside air temperature over time. Equations system and calculation model provided to count distribution of temperature in the ground and in the air of an underground tunnel, considering outside air temperature change [7].

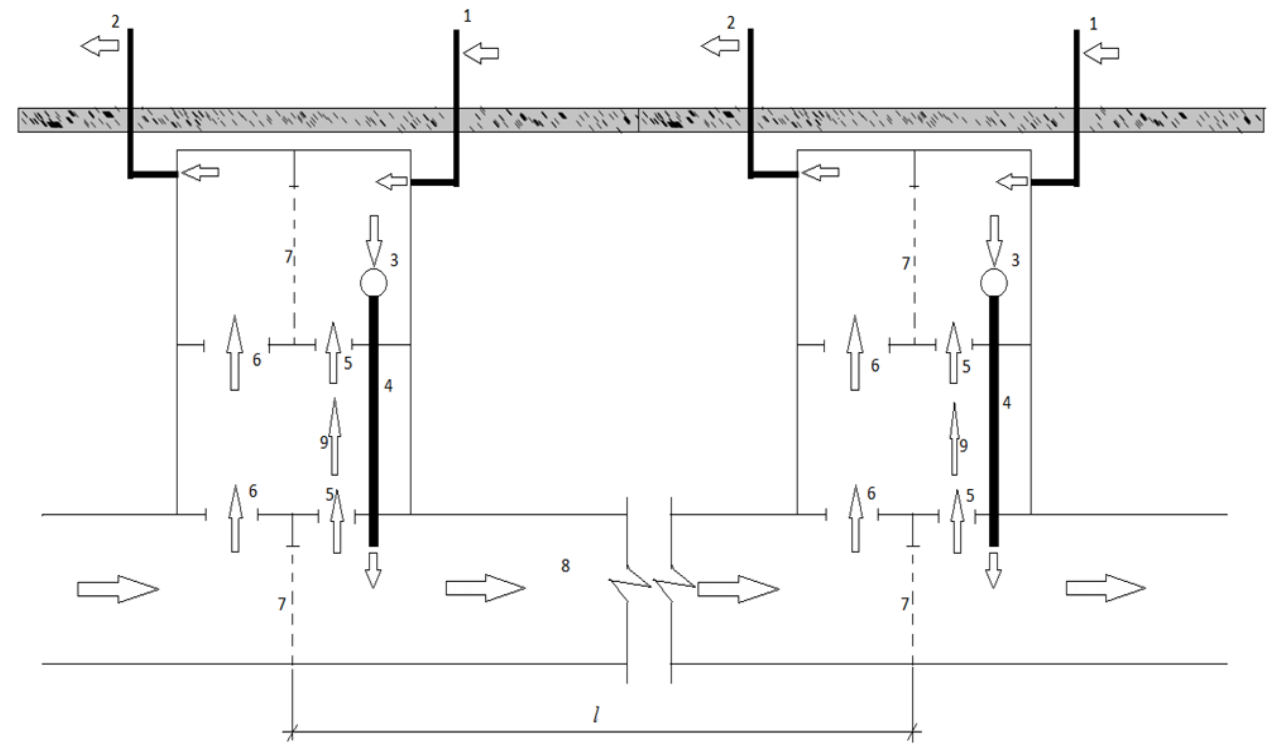

Fig. 1. Diagram of an underground tunnel with working system of mechanical ventilation, where $1-$ supply shaft, 2 - exhaust shaft, 3 - ventilator, 4 - air duct, 5 - natural ventilation with a ladder for personel, 6 - technical gap for exhaust air, 7 - door, 8 - underground tunnel, $l$-length of tunnel's part, 9 - recycling circuit

Movement of air and convective heat transfer into underground tunnels occurs in the module between supply and exhaust shafts. First air goes into supply shaft, then into tunnel's air and leaves through exhaust shaft into surface layer (Fig. 1). Supply and exhaust ventilation constantly works in the underground tunnel: supply ventilator provides air into the shaft. Part of the air goes into recycling circuit and mix with outside air before the ventilator. Then air goes to the tunnel and leaves through exhaust shaft [8]. It is assumed, that there is no natural air movement inside the tunnel. Thermal conditions of the underground tunnel for engineering communications are defined by the following thermal 
processes. Air, that goes into supply shaft, then into tunnel and then into the exhaust shaft, with working ventilation system, is in constant convective heat transfer with shaft and wall surface, with engineering communications surface [9]. With such transfer, air temperature, which depends on temperature of the air near the supply shaft, on the temperature of wall, shaft and engineering communications surface, changes. Temperature of wall and tunnel surface depends on heat transfer with air in the tunnel and on the heat transfer with wall surface through the wall itself and with the ground around the tunnel. Impact of change of the outside air temperature on the ground around the collector, wall surface and air temperature inside the tunnel depends on the depth of the tunnel [10]. There are deep-laid, medium-laid and shallow-lying tunnels. In the medium-laid and deep-laid tunnels impact of outside air temperature on the ground is either small or absent and heat transfer from tunnel air to the ground is most important.

As a result from the implementation of mathematical model of thermal conditions of air inside the tunnel and ground around it there are values of temperature from section to section on the whole length and distribution of temperature in the ground from box to box. Basic reference data: thermotechnical characteristics of reinforced concrete enclosing structure of the tunnel and of the surrounding ground, external and internal air, speed of the air inside the tunnel, temperature of engineering communications inside the tunnel. Air space inside the underground tunnel splits into cells $\delta \times \mathrm{h}_{\mathrm{c}} \times \mathrm{b}_{\mathrm{c}} \mathrm{m}$ size $(\delta-$ width of the cell, equal to $0,1 \mathrm{~m}, \mathrm{~h}_{\mathrm{c}}$ - height of the tunnel, $\mathrm{b}_{\mathrm{c}}-$ depth of the tunnel) (Fig. 2) and ground, around the tunnel, splits into cells $0,1 \times 0,1 \times 0,1 \mathrm{~m}$ (Fig. 3). In the first air cell basic reference data are described and the third boundary conditions are set [11]. Then equations system is resolved to find air temperature conditions in the air cells, walls and surrounding ground. If the high-voltage cable has been placed inside the tunnel, then air temperature in the tunnel must limited to $+30{ }^{\circ} \mathrm{C}-+40{ }^{\circ} \mathrm{C}$. This is related with keeping the durability and preservation of engineering communications and with normative conductivity of highvoltage cables. Thermal conditions of the tunnel depend on heat gain and heat loss. Heat gain occurs from the thermal network, electrical cables and from the outside air during the warm period of the year. Heat loss determined by the heat transfer with the surrounding ground, pipes of cold water supply, present in the tunnel and heating of the air during the cold and transitional period of the year [12].

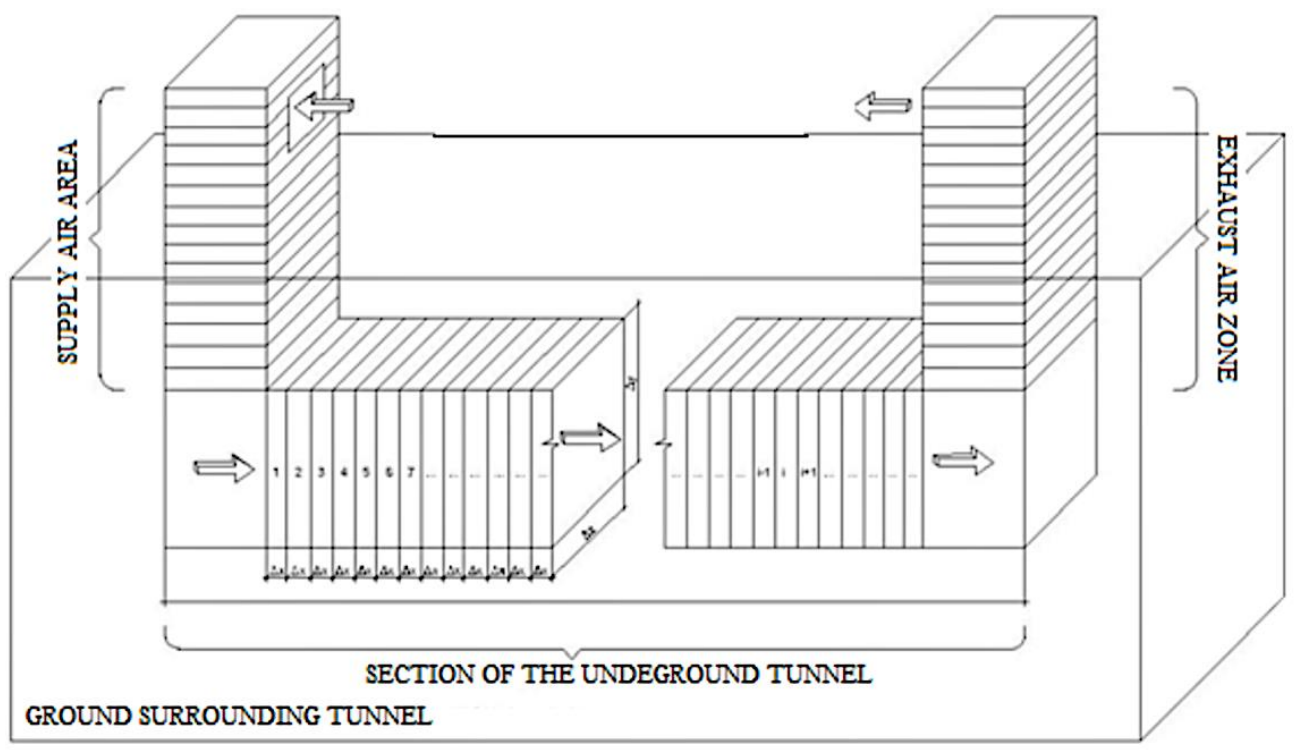

Fig. 2. Scheme for calculation of thermal conditions in the underground tunnel 


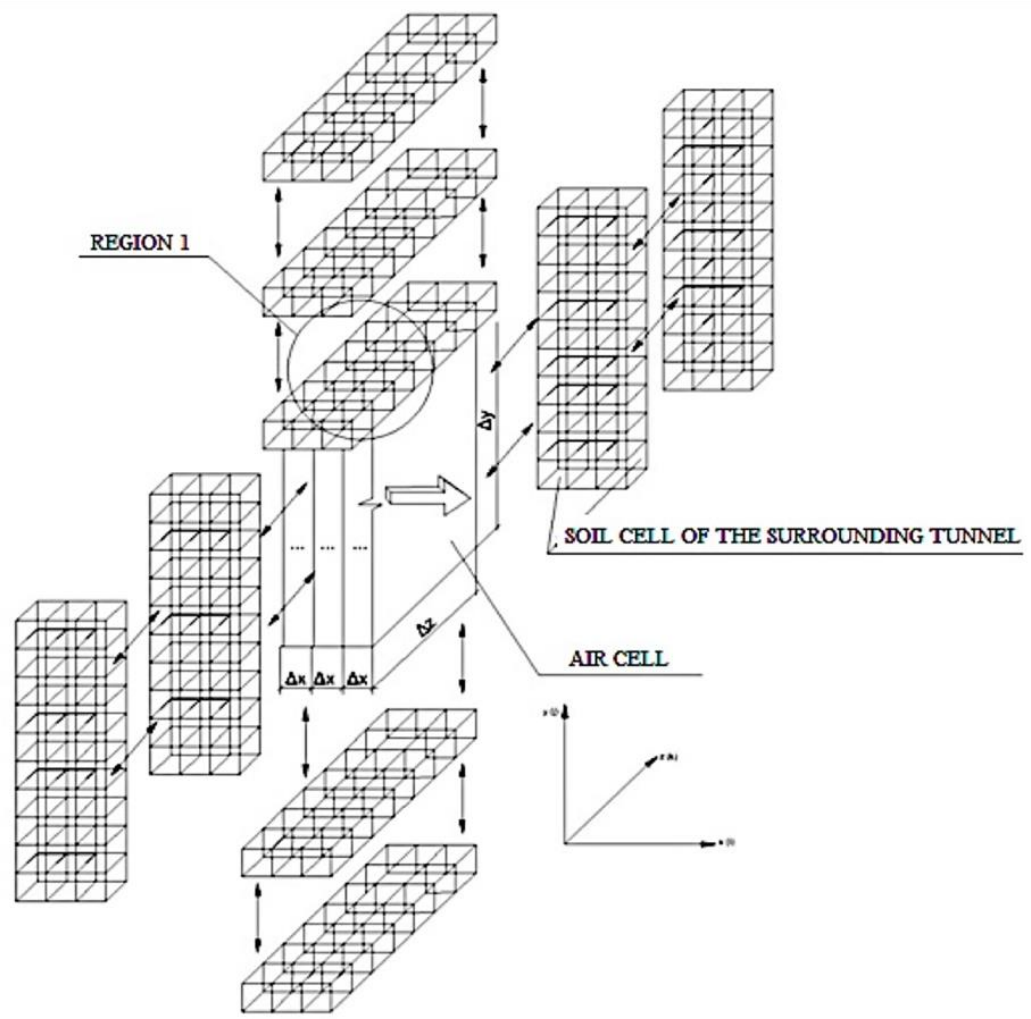

Fig. 3. Scheme of thermal conditions of the tunnel, taking into account surrounding ground

Scheme of tunnel's breakdown into cells for thermal conditions calculation, with air, ground and wall surface temperature calculation can be seen on the Fig. 3. Thermal conditions change in each cell along the path of the air. Air, wall and ground temperature also change together with thermal conditions [13]. Analysis of thermal conditions in the cells throughout the tunnel's length goes in the unsteady state, considering change of the external temperature over day, season, year, and decade. Thermal conditions depend on the movement of the air in the underground tunnel's space, as the air enter and transfer heat inside the tunnel, which should be noted for creation of mathematical model.

Equation for calculation of the thermal conditions inside the tunnel with numerical solution:

- Heat-balance equation in the air cell inside the tunnel:

$\Delta V_{a} \times \mathrm{c}_{a} \times \rho_{a} \times \frac{\Delta t_{a}}{\Delta \tau}=\frac{t_{1}-t_{a}}{\frac{1}{\alpha_{1}}} \times \Delta x \times \Delta z+\frac{t_{1}-t_{a}}{\frac{1}{\alpha_{2}}} \times \Delta x \times \Delta y+L \times c_{a} \times \rho_{a} \times$

$\Delta t_{a}+\sum \pm q(\tau) \times \Delta x$

where $q$ - heat flow from the engineering communications, W/m; $\Delta x \times \Delta z$ and $\Delta x \times \Delta y-$ area of walls inside one cell, $\mathrm{m}^{2} ; \Delta L-$ air flow, entering the cell due to the air movement in the tunnel over time, $\mathrm{m}^{3} / \mathrm{s} ; \mathrm{c}_{\mathrm{a}}$ and $\rho_{\mathrm{a}}$ - heat capacity and density of the air, $\mathrm{kJ} /\left(\mathrm{kg} \times{ }^{\circ} \mathrm{C}\right)$, $\mathrm{kg} / \mathrm{m}^{3} ; \Delta V_{a}=\frac{L}{S}-$ Dynamic volume of the cell into which the tunnel`s enclosing structures are split, $\mathrm{m} / \mathrm{s} ; S=\Delta y \times \Delta z ; \tau-$ time, $\mathrm{s}$. 
- Heat balance equation in the first cell, into which the enclosing structures of the tunnel are split:

$$
\begin{aligned}
& \Delta V_{c} \times \mathrm{c}_{c} \times \rho_{c} \times \frac{\Delta t_{1}}{\Delta \tau}=\frac{t_{i}-t_{1}}{\frac{1}{\alpha_{k}}} \times \Delta x \times \Delta z+\frac{t_{2}-t_{1}}{\frac{\delta_{1}}{2 \lambda_{1}}+\frac{\delta_{2}}{2 \lambda_{2}}} \times \Delta x \times \Delta z+\frac{t_{1.1}-t_{1}}{\frac{\delta_{1}}{2 \lambda_{1}}+\frac{\delta_{1.1}}{2 \lambda_{1.1}}} \times \Delta y \times \Delta z+ \\
& \frac{t_{1.2}-t_{1}}{\frac{\delta_{1}}{2 \lambda_{1}}+\frac{\delta_{1.2}}{2 \lambda_{1.2}}} \times \Delta y \times \Delta z+\frac{\frac{t_{1.3}-t_{1}}{2 \delta_{1}}}{\frac{\delta_{1}}{2 \lambda_{1}}+\frac{\delta_{1.3}}{2 \lambda_{1.3}}} \times \Delta x \times \Delta y+\frac{t_{1.4}-t_{1}}{\frac{\delta_{1}}{2 \lambda_{1}}+\frac{\delta_{1.4}}{2 \lambda_{1.4}}} \times \Delta x \times \Delta y
\end{aligned}
$$

where $\Delta x \times \Delta z, \Delta y \times \Delta z, \Delta x \times \Delta y-$ area of walls inside one cell, $\mathrm{m}^{2} ; \mathrm{c}_{\mathrm{c}}$ and $\rho_{\mathrm{c}}-$ heat capacity and density of the reinforced concrete enclosing structure of the tunnel, $\mathrm{kJ} /\left(\mathrm{kg} \times{ }^{\circ} \mathrm{C}\right), \mathrm{kg} / \mathrm{m}^{3} ; \Delta V_{c}=\Delta x \times \Delta y \times \Delta z-$ volume of the cell into which the tunnel's enclosing structures are is split, $\mathrm{m}^{3} ; \tau-$ time, $\mathrm{s} ; \delta$ - width of the cell in the tunnel's enclosing structure, $\mathrm{m} ; \lambda-$ thermal conduction of the enclosing structure's material, $\mathrm{W} /\left(\mathrm{m} \times{ }^{\circ} \mathrm{C}\right)$.

Size of the enclosing structure's and ground's cell was accepted equal to the width of the volatility layer.

- Heat balance equation in the rest of the cells, into which the surrounding ground is split:

$$
\begin{aligned}
& \Delta V_{g r} \times \mathrm{c}_{g r} \times \rho_{g r} \times \frac{\Delta t_{N}}{\Delta \tau}=\frac{t_{N-1}-t_{N}}{\frac{\delta_{N-1}}{2 \lambda_{N-1}}+\frac{\delta_{N}}{2 \lambda_{N}}} \times \Delta x \times \Delta z+\frac{t_{N+1}-t_{N}}{\frac{\delta_{N+1}}{2 \lambda_{N+1}}+\frac{\delta_{N}}{2 \lambda_{N}}} \times \Delta x \times \Delta z+\frac{t_{N 1}-t_{N}}{\frac{\delta_{N 1}}{2 \lambda_{N 1}}+\frac{\delta_{N}}{2 \lambda_{N}}} \times \\
& \Delta y \times \Delta z+\frac{t_{N 2}-t_{N}}{\frac{\delta_{N 2}}{2 \lambda_{N 2}}+\frac{\delta_{N}}{2 \lambda_{N}}} \times \Delta y \times \Delta z+\frac{t_{N 3}-t_{N}}{\frac{\delta_{N 3}}{2 \lambda_{N 3}}+\frac{\delta_{N}}{2 \lambda_{N}}} \times \Delta x \times \Delta y+\frac{t_{N 4}-t_{N}}{\frac{\delta_{N 4}}{2 \lambda_{N 4}}+\frac{\delta_{N}}{2 \lambda_{N}}} \times \Delta x \times \Delta y
\end{aligned}
$$

where $\Delta x \times \Delta z, \Delta y \times \Delta z, \Delta x \times \Delta y-$ area of walls inside one cell, $\mathrm{m}^{2}$; $\mathrm{c}_{\mathrm{gr}}$ and $\rho_{\mathrm{gr}}-$ heat capacity and density of the surrounding ground, $\mathrm{kJ} /\left(\mathrm{kg} \times{ }^{\circ} \mathrm{C}\right), \mathrm{kg} / \mathrm{m}^{3} ; \Delta V_{g r}=\Delta x \times \Delta y \times \Delta z-$ volume of the cell into which the ground is split, $\mathrm{m}^{3} ; \tau$ - time, $\mathrm{s} ; \delta$ - width of the ground's cell, $\mathrm{m} ; \lambda$ - thermal conduction of the layer, $\mathrm{W} /\left(\mathrm{m} \times{ }^{\circ} \mathrm{C}\right)$.

- Heat balance equation of the cell, which is connected to the outside air:

$$
\begin{aligned}
& \Delta V_{g r} \times \mathrm{c}_{g r} \times \rho_{g r} \times \frac{\Delta t_{e . f}}{\Delta \tau}=\frac{t_{e}-t_{e . f}}{\frac{1}{\alpha}} \times \Delta x \times \Delta z+\frac{t_{e . f-1}-t_{e . f}}{\frac{\delta_{e . f-1}}{2 \lambda_{e . f .1}}+\frac{\delta_{e . f}}{2 \lambda_{e . f}}} \times \Delta x \times \Delta z+\frac{t_{e . f 1}-t_{e . f}}{\frac{\delta_{e . f 1}}{2 \lambda_{e . f 1}}+\frac{\delta_{e . f}}{2 \lambda_{e . f}}} \times \\
& \Delta y \times \Delta z+\frac{t_{e . f 2}-t_{e . f}}{\frac{\delta_{e . f 2}}{2 \lambda_{e . f 2}}+\frac{\delta_{e . f}}{2 \lambda_{e . f}}} \times \Delta y \times \Delta z+\frac{t_{e . f 3}-t_{e . f}}{\frac{\delta_{e . f 3}}{2 \lambda_{e . f 3}}+\frac{\delta_{e . f}}{2 \lambda_{e . f}}} \times \Delta x \times \Delta y+\frac{t_{e . f 4}-t_{e . f}}{\frac{\delta_{e . f 4}}{2 \lambda_{e . f 4}}+\frac{\delta_{e . f}}{2 \lambda_{e . f}}} \times \Delta x \times \Delta y
\end{aligned}
$$

where $\Delta x \times \Delta z, \Delta y \times \Delta z, \Delta x \times \Delta y-$ area of walls inside one cell, $\mathrm{m}^{2}$; $\mathrm{c}_{\mathrm{gr}}$ and $\rho_{\mathrm{gr}}-$ heat capacity and density of the surrounding ground, $\mathrm{kJ} /\left(\mathrm{kg} \times{ }^{\circ} \mathrm{C}\right), \mathrm{kg} / \mathrm{m}^{3} ; \Delta V_{g r}=\Delta x \times \Delta y \times \Delta z-$ volume of the cell into which the ground, which is connected to the outside air, is split, $\mathrm{m}^{3}$; $\tau$ - time, h; width of the ground's cell, which is connected to the outside air, $\mathrm{m} ; \lambda$ - thermal conduction of the layer, $\mathrm{W} /\left(\mathrm{m} \times{ }^{\circ} \mathrm{C}\right)$.

Calculation of the thermal conditions of the underground tunnel is conducted with approximation with the ratio of finite differences of differential equations members for each air, ground and enclosing structure cell of the tunnel.

Heal balance equation system: 


$$
\begin{aligned}
& \int V_{a} \times c_{a} \times \rho_{a} \times \frac{\Delta t_{a}}{\Delta \tau}=\frac{t_{1}-t_{a}}{\frac{1}{\alpha_{1}}} \times \Delta x \times \Delta z+\frac{t_{1}-t_{a}}{\frac{1}{\alpha_{2}}} \times \Delta x \times \Delta y+\Delta L \times \\
& c_{a} \times \rho_{a} \times \Delta t_{a}+\sum \pm q \times \Delta x(\tau)(5) \\
& \Delta V_{c} \times \mathrm{c}_{c} \times \rho_{c} \times \frac{\Delta t_{1}}{\Delta \tau}=\frac{t_{i}-t_{1}}{\frac{1}{\alpha_{k}}} \times \Delta x \times \Delta z+\frac{t_{2}-t_{1}}{\frac{\delta_{1}}{2 \lambda_{1}}+\frac{\delta_{2}}{2 \lambda_{2}}} \times \Delta x \times \Delta z+\frac{t_{1.1}-t_{1}}{\frac{\delta_{1}}{2 \lambda_{1}}+\frac{\delta_{1.1}}{2 \lambda_{1.1}}} \times \Delta y \times \Delta z+ \\
& \frac{t_{1.2}-t_{1}}{\frac{\delta_{1}}{2 \lambda_{1}}+\frac{\delta_{1.2}}{2 \lambda_{1.2}}} \times \Delta y \times \Delta z+\frac{t_{1.3}-t_{1}}{\frac{\delta_{1}}{2 \lambda_{1}}+\frac{\delta_{1.3}}{2 \lambda_{1.3}}} \times \Delta x \times \Delta y+\frac{t_{1.4}-t_{1}}{\frac{\delta_{1}}{2 \lambda_{1}}+\frac{\delta_{1.4}}{2 \lambda_{1.4}}} \times \Delta x \times \Delta y \\
& \Delta V_{g r} \times \mathrm{c}_{g r} \times \rho_{g r} \times \frac{\Delta t_{N}}{\Delta \tau}=\frac{t_{N-1}-t_{N}}{\frac{\delta_{N-1}}{2 \lambda_{N-1}}+\frac{\delta_{N}}{2 \lambda_{N}}} \times \Delta x \times \Delta z+\frac{t_{N+1}-t_{N}}{\frac{\delta_{N+1}}{2 \lambda_{N+1}}+\frac{\delta_{N}}{2 \lambda_{N}}} \times \Delta x \times \Delta z+\frac{t_{N 1}-t_{N}}{\frac{\delta_{N 1}}{2 \lambda_{N 1}}+\frac{\delta_{N}}{2 \lambda_{N}}} \times \Delta y \times \Delta z+ \\
& \frac{t_{N 2}-t_{N}}{\frac{\delta_{N 2}}{2 \lambda_{N 2}}+\frac{\delta_{N}}{2 \lambda_{N}}} \times \Delta y \times \Delta z+\frac{t_{N 3}-t_{N}}{\frac{\delta_{N 3}}{2 \lambda_{N 3}}+\frac{\delta_{N}}{2 \lambda_{N}}} \times \Delta x \times \Delta y+\frac{t_{N 4}-t_{N}}{\frac{\delta_{N 4}}{2 \lambda_{N 4}}+\frac{\delta_{N}}{2 \lambda_{N}}} \times \Delta x \times \Delta y \\
& \Delta V_{g r} \times \mathrm{c}_{g r} \times \rho_{g r} \times \frac{\Delta t_{e . f}}{\Delta \tau}=\frac{t_{e}-t_{e . f}}{\frac{1}{\alpha}} \times \Delta x \times \Delta z+\frac{t_{e . f-1}-t_{e . f}}{\frac{\delta_{e . f-1}}{2 \lambda_{e . f .-1}}+\frac{\delta_{e . f}}{2 \lambda_{e . f}}} \times \Delta x \times \Delta z+\frac{t_{e . f 1}-t_{e . f}}{\frac{\delta_{e . f 1}}{2 \lambda_{e . f 1}}+\frac{\delta_{e . f}}{2 \lambda_{e . f}}} \times \Delta y \times \Delta z+ \\
& \frac{t_{e . f 2}-t_{e . f}}{\frac{\delta_{e . f 2}}{2 \lambda_{e . f 2}}+\frac{\delta_{e . f}}{2 \lambda_{e . f}}} \times \Delta y \times \Delta z+\frac{t_{e . f 3}-t_{e . f}}{\frac{\delta_{e . f 3}}{2 \lambda_{e . f 3}}+\frac{\delta_{e . f}}{2 \lambda_{e . f}}} \times \Delta x \times \Delta y+\frac{t_{e . f 4}-t_{e . f}}{\frac{\delta_{e . f 4}}{2 \lambda_{e . f 4}}+\frac{\delta_{e . f}}{2 \lambda_{e . f}}} \times \Delta x \times \Delta y
\end{aligned}
$$

where: (5) - Heat-balance equation in the air cell inside the tunnel; (6) - balance equation in the first cell, into which enclosing structures of the tunnel are split; (7) - Heat balance equation in the rest of the cells, into which the surrounding ground is split; (8) - Heat balance equation of the cell, which is connected to the outside air.

Changing over time value of air's temperature over the length of the tunnel in the enclosing structure and surrounding ground will be the solution of the heat balance system of equations.

\section{Results of the study}

A mathematical model of thermal conditions in the underground tunnel and its solution has been provided. Programming language FORTRAN and compiler Force 2.0 were chosen as the base of mathematical modeling. Ground temperature (initial) $\mathrm{t}_{\mathrm{gr} .0}$, ${ }^{\circ} \mathrm{C}$, internal air temperature $\mathrm{t}_{\mathrm{a}},{ }^{\circ} \mathrm{C}$, outside air temperature $\mathrm{t}_{\mathrm{i}},{ }^{\circ} \mathrm{C}$, temperature of the tunnel's enclosing structure $\mathrm{t}_{\text {s.i. }},{ }^{\circ} \mathrm{C}$, thermal conduction of the ground $\lambda_{\text {gr. }}, \mathrm{W} / \mathrm{m} \times{ }^{\circ} \mathrm{C}$, thermal conduction of the enclosing structure $\lambda_{\mathrm{en}}, \mathrm{W} / \mathrm{m} \times{ }^{\circ} \mathrm{C}$, heat capacity of the ground $\mathrm{c}_{\mathrm{gr}}, \mathrm{kJ} /\left(\mathrm{kg} \times{ }^{\circ} \mathrm{C}\right)$, heat capacity of the enclosing structure $\mathrm{c}_{\mathrm{en}}, \mathrm{kJ} /\left(\mathrm{kg} \times{ }^{\circ} \mathrm{C}\right)$, density of the ground $\rho_{\text {gr. }}, \mathrm{kg} / \mathrm{m}^{3}$, density of the enclosing structure's layers $\rho_{\mathrm{tn}}, \mathrm{kg} / \mathrm{m}^{3}$ were taken as the initial data [14].

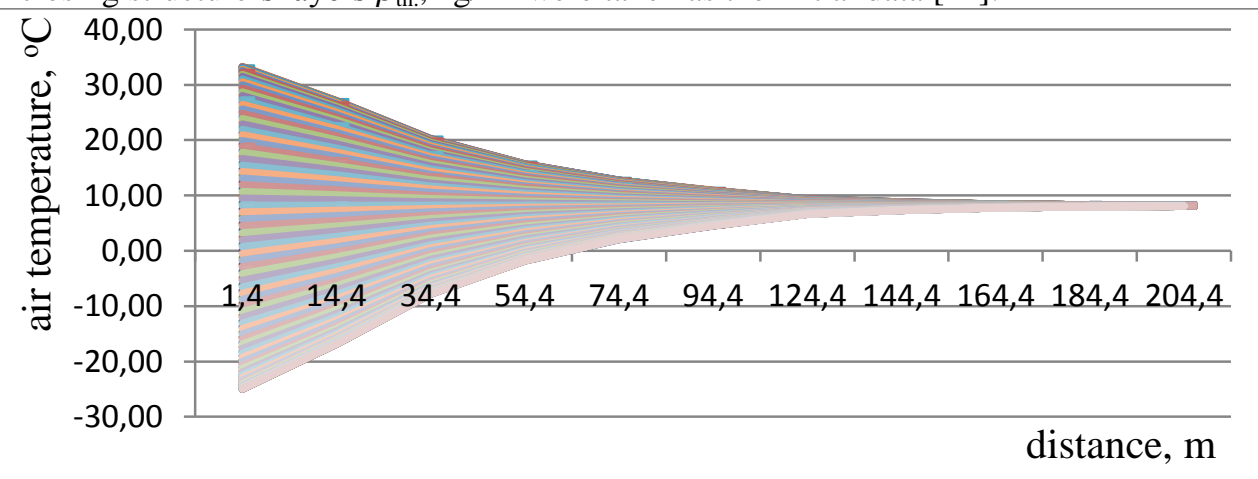

Fig. 4. Change of the air temperature in the tunnel over its length within the outside air temperature range from $-25{ }^{\circ} \mathrm{C}$ to $32{ }^{\circ} \mathrm{C}$ over the year 
The underground tunnel, with insulated electric cables and communication cables, was taken for calculations. There was no heating of the supplied air during the cold season of the year. Part of an underground tunnel 250 meters long from supply to exhaust ventilation was taken as an object of research. The tunnel with surrounding ground is divided into two symmetrical parts. One of them is split into cells. A three-dimensional model of the tunnel and surrounding ground with X (i), Y (k), Z (j) axis and of the following size: height $-7 \mathrm{~m}$, width $-4.5 \mathrm{~m}$, length $-262 \mathrm{~m}$, was examined. Cell of air space of the tunnel, with size $0,1 \times h_{c} \times b_{c}$ m, was taken as the element of calculation. The number of such elements is equal to $2524 \mathrm{pcs}$. The ground is split into cells, with size $0,1 \times 0,1 \times 0,1 \mathrm{~m}$, in the number, equal to $70 \times 2620 \times 45$ pcs. Change of the air temperature (for air cells) and temperature of the enclosing structure and the ground (for enclosing structure and ground temperature) is calculated for each cell, considering the impact of the neighboring cells and dynamics of outside air temperature over the season, year and decade. Graphs of the temperature change over the length of the tunnel were plotted. From them (Fig. 4) it can be seen, that air temperature inside the tunnel is stabilized $170 \mathrm{~m}$ after the supply shaft, and it's value is equal to $+8{ }^{\circ} \mathrm{C}$. It's connected to the surrounding ground's temperature. On the Fig. 5 graphs of temperature's change are plotted, depending on the time and on the length from the supply shaft equal to $1,4 \mathrm{~m}, 14,4 \mathrm{~m}, 34,4 \mathrm{~m}, 54,4 \mathrm{~m}, 74,4 \mathrm{~m}, 94,4 \mathrm{~m}, 124,4 \mathrm{~m}, 144,4 \mathrm{~m}$, $164,4 \mathrm{~m}, 184,4 \mathrm{~m}, 204,4 \mathrm{~m}$ considering the outside air temperature change [15].

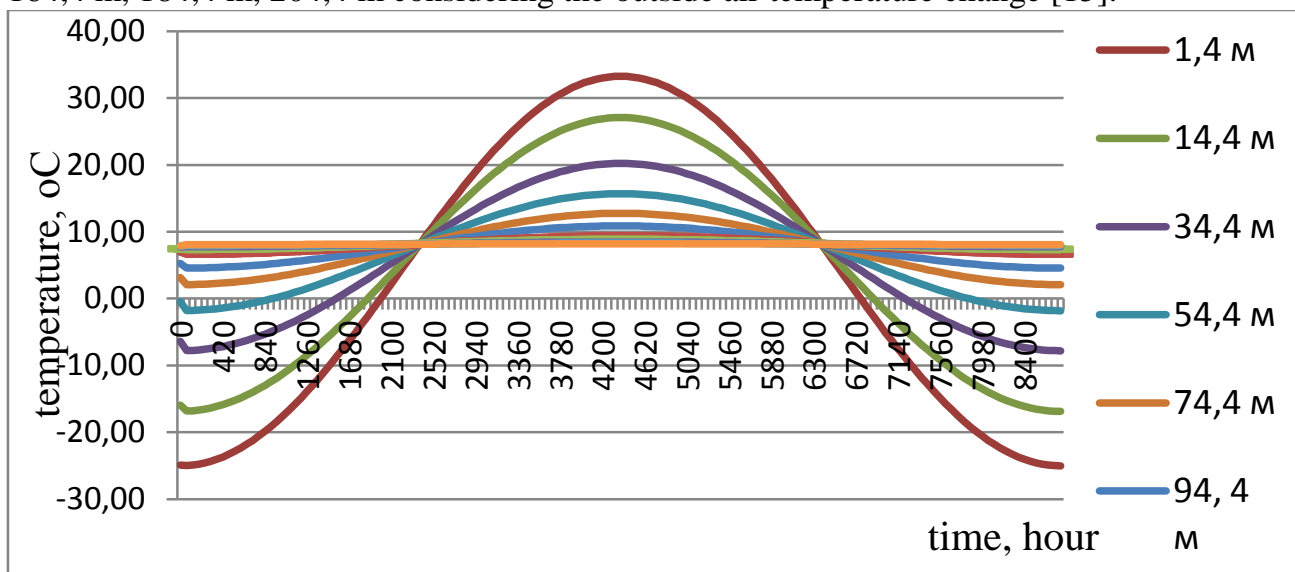

Fig. 5. Graphs of the internal air temperature change, depending on the time, length of the tunnel and the external temperature change

Changes of temperature maximums of the graphs (Fig. 5) are almost unnoticeable due to the low thermal density of the air. Temperature change amplitude decreases going from the supply shaft over the length of the tunnel. Combination of cell's sizes, iterative calculation's time step and total calculation time allowed solving the task with sufficient accuracy.

\section{Conclusions}

1. Mathematical model, based on the calculation of three-dimensional nonstationary thermal conditions of ground and enclosing structures allows to define heal loss of the underground tunnel for engineering communications. This heat loss impacts the thermal conditions of the underground tunnel with any combination of outside air temperature, thermophysical parameters of the ground and heat gain and heat loss in the air of the tunnel. 2. Suggested mathematical model, based on the calculation of two-dimensional nonstationary thermal conditions of the tunnel's air space, with air, flowing over the underground tunnel for engineering communications, considering the three-dimensional 
calculation of thermal conditions of the ground and enclosing structures of the tunnel, allows to define change of the air's temperature in the tunnel 250 meters long from supply to exhaust ventilation, considering outside air temperature, thermophysical parameters of the ground and heat gain and heat loss in the air of the tunnel.

3. Analysis of the thermal conditions change in the ground, surrounding the tunnel allowed defining of the impact of external temperature change on the internal air temperature, which is changing over time and length of the tunnel.

4. Suggested method of calculation of thermal conditions for underground tunnel for engineering communications, allows defining phase shifts for minimum and maximum of the internal air temperature, considering the external temperature change. This is important to form the required microclimate inside the tunnel's air space.

\section{References}

1. ASHRAE Guide And Data Book:Fundamentals and Air Conditioning Engineering. 1963, $912 \mathrm{p}$.

2. Carpenter S B, 1970, et.al. Principal Plum Dispersion Models. TVA Pow. Plants, 63 Annual Meeting, Air Pollution Assoc., June.

3. Frenkiel F N, Munn R E, 1974, eds. Turbulent Diffusion in Enviromental Pollution. Advances in Geophysics Series, vols. 18A and 18B, New-York, Academic Press.

4. Huber A N, 1977, Incorporating Building. Terrain Wake Effects on StaskEnfluent, Preprint Volume for the Joint Conf. on Applic. of Air Pollut. Metod., Amer. Meteorolog. Socity, Boston, MA.

5. Roberts O, 1923, The Theoretical of Smoke in a turbulent atmosphere. Proc. Roy. Soc. 104A, pp.11-15.

6. Overcamp T, 1975, General Gaussian Diffusion - Deposition Model of Elevated Point Souces, Journal of Applied Meteor. 15, pp. 1167-1171.

7. Skaret E A, Mathisen H M, 1982, Ventilation Efficiency. Enviroment International, 8, pp. 473-481.

8. Tuve G L, 1953, Air Velocities in ventilating jets. - Trans. ASHRAE, v. 59, pp. 261282.

9. Woods J E, Crawford R R, 1983, Calculation Methods to Assess Indoor Air Quality. ASHRAE Transactions, pp. 683-696.

10. Woods J E, 1975, Influence of Room Air Distribution on Animal Cage Environiments. Trans. ASHRAE, pp. 559-571.

11. Brukhanov O, Rymarov A, Malysheva A, Titkov D, 2016, Analysis of heat losses of underground tunnel for engineering utilities with available methods, MATEC WEB OF CONFERENCES 5. Cep. "5th Inter. Scien. Conf. "Integration, Partnership and Innovation in Construction Science and Education".

12. Rymarov A G, Titkov D G, 2015, Peculiarities of calculation of thermal regime of underground communication collector internet bulletin wolghas, Volgograd State University of Architecture and Civil Engineering (Volgograd) No 4(40), p. 6.

13. Rymarov A G, Titkov D G, 2015, Influence of the massity of the environment on the thermal regime of the underground collector for engineering communications, natural and technical sciences, OOO "Izd." Sputnik + "(Moscow), No 6(84), pp. 563-564.

14. Brukhanov O N, Rymarov A G, Titkov D G, 2015, Analysis of methods of calculation of thermal losses by underground mounting collector, natural and technical sciences, OOO "Izd." Sputnik + "(Moscow), No 8(86), pp. 89-91.

15. Rymarov A G, Titkov D G, 2015, Analysis of thermal losses by underground collector by methodology b.a. kazantseva, scientific review Izdat. dom "Science of Education" (Moscow), No 10-2, pp. 44-47. 